\title{
BMJ Global Health Maternal and child health services and an integrated, life-cycle approach to the prevention of non- communicable diseases
}

\author{
Luisa Brumana, ${ }^{1}$ Alvaro Arroyo, ${ }^{2}$ Nina R Schwalbe, ${ }^{3}$ Susanna Lehtimaki, ${ }^{4}$ \\ David B Hipgrave ${ }^{5}$
}

To cite: Brumana L, Arroyo A, Schwalbe NR, et al. Maternal and child health services and an integrated, life-cycle approach to the prevention of non-communicable diseases. BMJ Glob Health 2017;2:e000295. doi:10.1136/ bmjgh-2017-000295

- Additional material is published online only. To view please visit the journal online (http://dx.doi.org/10.1136/ bmjgh-2017-000295).

Received 22 January 2017 Revised 10 April 2017 Accepted 30 April 2017

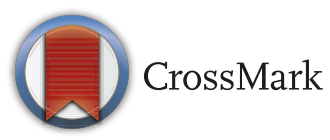

${ }^{1}$ UNICEF Regional Office for Latin America and the Caribbean, Panama City, Panama

${ }^{2}$ UNICEF Country Office, Montevideo, Uruguay ${ }^{3}$ Spark Street Consulting, New York City, New York, USA ${ }^{4}$ UNICEF Country Office, Almaty, Kazakhstan

${ }^{5}$ UNICEF HQ, New York City, New York, USA

Correspondence to Dr David B Hipgrave; dhipgrave@gmail.com

\section{ABSTRACT}

Described as the 'invisible epidemic', non-communicable diseases (NCDs) are the world's leading cause of death. Most are caused by preventable factors, including poor diet, tobacco use, harmful use of alcohol and physical inactivity. Diabetes, cancer and cardiovascular and chronic lung diseases were responsible for 38 million $(68 \%)$ of global deaths in 2012. Since 1990, proportionate NCD mortality has increased substantially as populations have aged and communicable diseases decline. The majority of NCD deaths, especially premature NCD deaths $(<70$ years, $82 \%$ ), occur in low-income and middle-income countries, and among poor communities within them. Addressing NCDs is recognised as central to the post2015 agenda; accordingly, NCDs have a specific objective and target in the Sustainable Development Goals. While deaths from NCDs occur mainly in adulthood, many have their origins in early life, including through epigenetic mechanisms operating before conception. Good nutrition before conception and interventions aimed at preventing NCDs during the first 1000 days (from conception to age 2 years), childhood and adolescence may be more costeffective than managing established NCDs in later life with costly tests and drugs. Following a life-course approach, maternal and child health interventions, before delivery and during childhood and adolescence, can prevent NCDs and should influence global health and socioeconomic development. This paper describes how such an approach may be pursued, including through the engagement of non-health sectors. It also emphasises evaluating and documenting related initiatives to underwrite systematic and evidence-based cross-sectoral engagement on NCD prevention in the future.

\section{BACKGROUND}

Over recent decades, many countries have undergone enormous transition in demography and disease epidemiology, with falling rates of preventable communicable diseases and increased life expectancy. However, the global prevalence of chronic, non-communicable diseases (NCDs) has risen dramatically, causing an estimated 38 million $(68 \%)$ of all deaths in 2012. ${ }^{1}$ NCDs are medical conditions

\section{Key questions}

Non-communicable diseases (NCDs) are the dominant cause of global morbidity and mortality; the risk of some acquired NCDs begins early in life and even before conception.

- New evidence reviews presented here suggest that many NCDs can be prevented with appropriate approaches across the maternal and child health (MCH) life-cycle, throughout the years of reproductive age (especially before conception and continuing through pregnancy), and during infancy, childhood and adolescence.

- The evidence reviewed also suggests that a multisectoral approach to reducing the risk of NCDs is needed, spanning the MCH life-cycle and involving public policy and regulation, improved health literacy and behaviour change interventions.

or diseases that are by definition non-infectious and non-transmissible; they are usually of long duration and slow progression, and often require costly long-term or lifelong treatment. WHO prioritises four groups of NCDs: cardiovascular diseases (responsible for $46.2 \%$ of NCD deaths), cancers (21.7\%), chronic respiratory diseases $(10.1 \%)$ and diabetes $(4.0 \%) .{ }^{1}$ Four modifiable behavioural risk factors are major contributors to their development: tobacco use, unhealthy diet, physical inactivity and harmful use of alcohol. ${ }^{23}$

Many reports confirm that NCDs are becoming a major burden on the global economy, and predominantly impact poor countries, poor communities and the poorest individuals within all nations. Low-income and middle-income countries (LMICs) bear $82 \%$ of the burden of premature NCD deaths, with predicted cumulative economic losses of US $\$ 7$ trillion over the next 15 years. ${ }^{1}$ The importance and urgency of addressing NCDs were reflected in the third Sustainable 
Development Goal (SDG3): 'Ensure healthy lives and promote well-being for all at all ages', with a specific target of reducing, by one-third by 2030 , premature mortality (before age 70 years) from NCDs, through prevention and treatment. ${ }^{4}$

Although NCDs have their major impact on global mortality and morbidity in adulthood, they also have significant impact on children and adolescents. In addition to the indirect effect of adult NCDs on child and adolescent well-being and opportunity, burgeoning childhood obesity has a direct and negative impact on mental and emotional well-being, peer relations, and learning and opportunities to participate in education and recreation. ${ }^{5}$ Moreover, the risk of adult NCDs is often established very early in life ${ }^{6}$ and is linked to adolescent body mass index. ${ }^{7}$ Many behaviours related to the development of NCDs are adopted during childhood and adolescence, ${ }^{89}$ but services intended for this age group tend to focus on more immediate issues and risks. ${ }^{9}$

Accordingly, to address the global burden of NCDs, a gradual shift in the focus of maternal and child health $(\mathrm{MCH})$ programmes is required, beyond survival and onto healthy child and adolescent development. Along with the SDG focus on lifelong well-being, this is acknowledged in the United Nations (UN) Secretary General's Global Strategy for Women's, Children's and Adolescents' Health, ${ }^{10}$ which calls on member states to end preventable maternal and child mortality, and to emphasise thriving (appropriate growth and well-being) and transforming the environment to promote lifelong good health. The Strategy's 'survive, thrive and transform' agenda provides the foundation for an early-life focus on long, productive and healthy life, including through a multisectoral approach to the prevention of adult NCDs. ${ }^{10}$

The role of $\mathrm{MCH}$ programmes on reducing NCD risk was highlighted in the outcome document of the second, high-level meeting on NCDs at the UN in 2014. This paper argues further for a new paradigm in global $\mathrm{MCH}$ programmes, one that emphasises the continuum of influences on and opportunities for assuring long-term good health, across the life-cycle. It therefore focuses on approaches to reducing the risks for developing adult NCDs among children and adolescents, the dominant risk to their lifelong health and well-being, and a major influence on future social and economic development.

\section{THE LIFE-CYCLE APPROACH, EARLY INTERVENTION, EQUITY AND ENVIRONMENTAL INFLUENCES ON NCD RISK}

While the majority of NCD deaths occur in adulthood, many have their origins in early life, including through epigenetic mechanisms operating before conception, even among men. ${ }^{611}$ Prenatal maternal undernutrition and low birth weight predispose to obesity, high blood pressure, heart disease and diabetes later in life ${ }^{12}{ }^{13}$; similarly, maternal obesity and gestational diabetes are associated with cardiovascular disease and diabetes for both the mother and her child. ${ }^{13}{ }^{14}$ Exposure to such
NCD risk factors may begin before or during pregnancy, and continue during infancy and childhood, underlining the importance of action across these age groups. ${ }^{6}{ }^{15}$ Moreover, in addition to their early adoption, ${ }^{9}$ many modifiable NCD risk behaviours are worsened by inherited (but preventable) physiological responses. ${ }^{6}$ Accordingly, a life-cycle approach to the primary prevention of NCDs has accrued more resonance as understanding increases on the interplay between consumption, physical activity, physiology, biochemistry and disease outcomes. ${ }^{9}$

This life-cycle approach to NCD prevention should begin when establishment of habits and life perspectives is greatest. ${ }^{9} 1617$ Programmes focusing on appropriate diet, lifestyle and behaviour, and targeting older children and adolescents, girls in particular, should influence NCD risk. Apart from directly benefiting children and adolescents, a focus on NCD prevention might influence health before and during pregnancy, and future parents' approaches to infant and young child care. ${ }^{13} 18$

NCDs disproportionately affect low socioeconomic groups, both across and within countries. Major NCD risk factors and NCD mortality are more prevalent in LMICs than in high-income countries, and risk factors such as tobacco smoking and high blood pressure are higher in poor or marginalised communities. ${ }^{19}$ For equitable health and socioeconomic progress, NCD prevention should accordingly be given very high priority, even in nations still struggling to reduce preventable young child and maternal mortality.

Moreover, environmental factors directly and indirectly influence the risk of future NCDs. Crowded and unsafe built environments, unsanitary living conditions, poor access to healthy diet options, high-stress family and community environments, interpersonal violence, lack of adult supervision and poverty all influence the establishment of NCD risk during childhood and adolescence. ${ }^{20}{ }^{21}$ These influences affect young men and women differently; for example, men may have greater access to tobacco and alcohol but also more opportunities for physical activity, while women's opportunities may be limited by unsafe environments and poor sanitation and hygiene facilities.

Solely addressing behavioural risk factors for NCDs and not the contributing social and environmental context may limit the impact on reducing their growing burden. This should be considered in establishing cross-sectoral linkages between interventions that directly prevent NCDs, and others that have an indirect but equally important impact across the life-cycle. ${ }^{22}$

\section{EXISTING EVIDENCE ON EFFECTIVE INTERVENTIONS TO PREVENT NCDS ACROSS THE LIFE-CYCLE}

Two UNICEF offices recently reviewed the literature on interventions with proven or likely impact on preventing NCDs and their risk factors among children and adolescents. ${ }^{23} 24$ These wide-ranging reviews fill a gap in the related evidence on this topic. Both used a 
Table 1 Interventions and approaches for which evidence exists of effectiveness for non-communicable disease (NCD) prevention among children and young people* by life-course stage or socioecological platform

\section{Description of interventions and approaches}

Source of evidence

Prenatal: maternal micronutrient supplementation; prevents low birth weight, which is associated Haider and Bhutta ${ }^{45}$ with subsequent NCD risk

Infancy: breast feeding and appropriate complementary feeding, which reduce later overweight, type Victora et al ${ }^{26}$ 2 diabetes and possibly high cholesterol and blood pressure

School-based: school policies and multicomponent interventions targeting behaviour risk factors at a young age, including school curricula on healthy eating, physical activity and body image,

Waters et $a l^{46}$ improvement in the nutritional quality of food supplied in schools, provision of free or subsidised fruit Baird et al ${ }^{48}$ and vegetables, health promotion strategies and parent support

Rawal et al ${ }^{49}$

Dudley et $\left.a\right|^{50}$

Liao et $\left.a\right|^{51}$

Seo and $\mathrm{Sa}^{52}$

Household: family interventions that support parents to model healthy behaviours to their children

Foxcroft and

Tsertsvadze ${ }^{53}$

Saraf et $a l^{54}$

Household: engagement of parents in supporting and encouraging their children's physical activity;
monitoring or regulating screen-time
Across platforms: interventions combined in schools, homes, primary care clinics, childcare settings
and within communities; these are more effective than stand-alone interventions
and within communities; these are more effective than stand-alone interventions

Pereira and Palmeira Biddle et $\left.a\right|^{56}$

Wang et $a l^{57}$

Oude Luttikhuis et $\left.a\right|^{58}$ Brand et $a l^{59}$

Adolescence: use of information and communications technologies (computer and web-based Chen and Wilkosz ${ }^{60}$ interventions) to improve eating behaviours and/or diet-related physical outcomes Hamel and Robbins ${ }^{61}$

Policy and community action: campaigns against tobacco consumption that are based on theory and formative research and delivered with a reasonable intensity over an extended period of time

\begin{abstract}
Across platforms: universal family-based and school-based substance abuse prevention, including tobacco use programmes
\end{abstract}

Policy and legislative action: government policies to control tobacco and alcohol through taxation, marketing and sales restrictions, bans in public places, and minimum age for purchase

Policy and legislative action: pricing policies, subsidies for healthy foods; taxation and control of marketing of unhealthy foods and beverages, including food labelling, and social marketing campaigns

*Based on two U UNICEF literature reviews undertaken in 2015-2016.

socioecological approach to examining the influence of various interventions/approaches on various NCD risk factors early in life. Both concentrated on reviews of reviews, policy statements from normative agencies and meta-analyses of primary data. Published, peer-reviewed and grey literature was included and standard literature search methodologies were used; one of the reviews ${ }^{23}$ sought information in several languages. Some evidence of effectiveness was found for certain interventions (table 1), including nutrition interventions; schoolbased policies and activities; interventions that combine the home, the local environment and schools; information technology and media-based approaches; and public policy on pricing, taxation, sale and marketing of consumable items. However, the overwhelming majority of the evidence emanates from high-income settings, and the authors of one of the reviews ${ }^{24}$ specifically cautioned against extrapolation to LMICs; the other reviewers only noted some evidence for school-based interventions in LMICs. The absence of 'silver-bullet' health technologies (eg, vaccines, specific nutrition interventions) or policies to reduce NCD risk calls for wide-ranging, long-term and cross-sectoral approaches implemented with high-level global, regional and national support. ${ }^{25}$

\section{POTENTIAL ENTRY POINTS FOR NCD PREVENTION IN MCH PROGRAMMES}

Recognising the importance of a cross-sectoral approach, there are opportunities for integrating NCD prevention in MCH programmes across the life-cycle. Many of the same activities that impact child survival and child and adolescent health can directly influence policy, practices, resources and behaviours that reduce NCD risk. 
Table 2 Existing and potential opportunities to reduce risk of non-communicable diseases by life-cycle period

1000 days* 2-5years 6-10years

10-19years

\begin{tabular}{|c|c|c|c|c|}
\hline Opportunities for action & & & & \\
\hline Improved health literacy and good nutrition before conception & $\mathrm{x}$ & & & \\
\hline $\begin{array}{l}\text { Good nutrition in pregnancy: prevention of poor or excessive weight } \\
\text { gain and/or anaemia }\end{array}$ & $x$ & & & \\
\hline $\begin{array}{l}\text { Healthy pregnancy: adequate number and quality of antenatal care } \\
\text { checks }\end{array}$ & $\mathrm{x}$ & & & \\
\hline Zero alcohol/illicit drugs during pregnancy and breast feeding & $\mathrm{x}$ & & & $\mathrm{x}$ \\
\hline Antiretroviral treatment to reduce HIV-related NCDs & $\mathrm{X}$ & & & \\
\hline Vaccination against hepatitis B to prevent cirrhosis and liver cancer & $x$ & & & \\
\hline Protective environment to reduce the behaviour impact of 'toxic stress' & $\mathrm{x}$ & $\mathrm{X}$ & $\mathrm{X}$ & $\mathrm{x}$ \\
\hline $\begin{array}{l}\text { Breast feeding and adequate complementary feeding of children } \\
6-23 \text { months and up to } 5 \text { years }\end{array}$ & $\mathrm{x}$ & $x$ & & \\
\hline Adequate physical activity in early life & $\mathrm{x}$ & $\mathrm{x}$ & $\mathrm{X}$ & $\mathrm{x}$ \\
\hline Non-exposure to/consumption of tobacco & $\mathrm{x}$ & $\mathrm{X}$ & $\mathrm{x}$ & $\mathrm{x}$ \\
\hline Good quality health services that reach children and their families & $\mathrm{x}$ & $\mathrm{x}$ & $x$ & $\mathrm{x}$ \\
\hline Promotion of a healthy diet & $x$ & $x$ & $x$ & $x$ \\
\hline Treatment of streptococcal infection & $x$ & $x$ & $x$ & $x$ \\
\hline Prevention of exposure to air pollution & $x$ & $x$ & $x$ & $x$ \\
\hline $\begin{array}{l}\text { Responsive rearing practices, positive stimulation, good parenting } \\
\text { (regarding diet and physical activity) }\end{array}$ & & $\mathrm{X}$ & $\mathrm{x}$ & \\
\hline $\begin{array}{l}\text { Provision and promotion of healthy eating habits and physical activity in } \\
\text { community-based programmes, child care and development services, } \\
\text { preschools, and schools (including through policy, legislative and other } \\
\text { regulatory approaches) }\end{array}$ & & $x$ & $x$ & $x$ \\
\hline $\begin{array}{l}\text { Life skills, including social and emotional learning at school; promotion } \\
\text { of resilience at school, in families and communities }\end{array}$ & & & $x$ & $x$ \\
\hline $\begin{array}{l}\text { Vaccination against the human papilloma virus to prevent genital warts } \\
\text { and cervical cancer }\end{array}$ & & & & $x$ \\
\hline
\end{tabular}

${ }^{*}$ The period from conception to age 2 years.

Breastfeeding promotion and support is a very concrete example. Until recently, breastfeeding promotion focused on its child survival benefit, and not that appropriate breast feeding probably reduces the risk of overweight and type 2 diabetes among children later in life, and women's risk of breast and ovarian cancer and type 2 diabetes. ${ }^{26}$ Similarly, incorporating an NCD focus into antenatal care (focusing on weight gain, micronutrient supplementation and physical activity) and early child care should be relatively simple in any context. Other examples include a focus on the nutritional status of adolescent girls and women before conception, appropriate infant and young child feeding, ${ }^{15}$ and the nutrition and activity levels of young children and adolescents. While these interventions have not been rigorously linked to a reduced risk of NCDs, they resonate with the evidence on the related pathophysiology. ${ }^{6}$ Diagnosis and treatment of streptococcal infections with penicillin to reduce the incidence of rheumatic heart disease and preventable renal failure, both major NCDs, should also be improved. Table 2 lists existing or new public health programmes or approaches that have potential to prevent the four major NCDs and some other NCDs, the risks for which are acquired early in life. The evidence for many of these approaches is summarised in the two reviews mentioned above, ${ }^{23} 24$ or is already well established.

It may be efficient, in countries where the epidemiological profile calls for immediate action (high rates of childhood overweight, adolescent smoking and alcohol abuse, pregnancy nutrition risks), to incorporate these interventions into existing national programmes, with new priority on NCD prevention. In some cases, and with appropriate monitoring and evaluation, this may contribute to the knowledge base on their effectiveness in the medium and long term. Indeed, given the dearth of evidence in LMIC, independent evaluation should be a key focus of any work labelled as contributing to NCD risk reduction.

In addition to combining NCD prevention with established interventions, MCH programmes are also well placed to support trials of new health technologies related to NCDs, such as newborn and child health screening 
programmes, the use of biomarkers to assess for risk of NCDs in later life, the impact of early-life antibiotics on NCD risk, ${ }^{27}$ and affordable technologies and drugs for the detection and management of NCDs. Screening and early identification of NCD risk in childhood and adolescence has great potential for cost-effective prevention of the development of NCDs in later life.

\section{THE IMPORTANCE OF DATA AND EVIDENCE}

Outcomes targeted by existing health, nutrition and education programmes currently focus on traditional indicators such as mortality or morbidity, delivery care, underweight/stunting, vaccination coverage, school attendance, literacy and so on, usually disaggregated by sex and sometimes by age group, socioeconomic status and subnational location. To the extent that NCD prevention and control is included as a specific element of government programming or advocacy, appropriate indicators should be developed and included in reporting at all levels. This will enable appropriate advocacy and monitoring of publicly funded or behaviour change-focused programmes, which may not be popular with all groups, especially those against the so-called 'nanny state' approaches. Maintenance of progress on such indicators aligns with the WHO Global Action Plan on NCDs, which calls for monitoring the determinants of and progress on NCD prevention. ${ }^{2}$ Key indicators on NCD prevention should also be added to periodic household surveys such as Demographic and Health Surveys, Multi-Indicator Cluster Surveys and Living Standards Measurement Surveys. Ideally biological markers and NCD risk status should also be assessed regularly through screening at schools or in the community. Related national policy and regulations, and their enforcement, should also be monitored through appropriate process or outcome indicators, as already suggested with related guidelines by the UN Interagency Task Force on NCDs. ${ }^{28}$

While there is good evidence on the cost of inaction on NCDs, and also on the cost-effectiveness of many related actions, ${ }^{29}$ there is little information on the economic impact of preconception and early-life prevention. Monitoring of MCH and school-based programmes could help to fill this knowledge gap and to support related advocacy and policy-level work at various levels; this needs to be prioritised immediately.

As an initial step to synthesise the available data, UNICEF and the Toronto Hospital for Sick Children developed regional profiles on key NCD outcomes and risk factors that can support agencies working to move forward on NCD prevention (table 3). These profiles provide support for the known association of early child undernutrition on the risk of adult NCDs, ${ }^{1530}$ and highlight regional differences in related risk factors and the potential for reducing the future NCD burden of countries characterised by the averages presented.
PROMOTING A MULTISECTORAL APPROACH TO NCD RISK REDUCTION ACROSS THE LIFE-CYCLE

Because social determinants and factors outside the health sector have such a strong influence on NCD risk and outcomes, prevention during childhood and adolescence requires comprehensive multisectoral action, including through the education sector, the food and beverage industry and agriculture, transport systems and built environments, and by the media. ${ }^{51}$ These are summarised below, with more suggestions provided in the online supplementary material. Appropriate and broad public sector and civil society engagement is required for such actions to be effective, in the same way as multisectoral engagement has mobilised action on climate change and the environment, for example.

The education sector has a clear role in reducing future NCD risk among children and adolescents. Existing evidence strongly suggests that preschool, primary and secondary school programmes influence dietary consumption, participation in physical activity and attitudes to exercise, raise awareness and establish norms that can influence entire households. ${ }^{17}$ Education programmes may indirectly contribute to NCD prevention through life-skills education and influencing attitudes to physical activity, diet, tobacco and alcohol. ${ }^{32}$

An increasing body of evidence suggests that adolescent health, nutrition and physical activity are closely related to adult NCD risk. ${ }^{73}$ Moreover, adolescents everywhere have an increasing ability to participate in the design and impact of programmes benefiting or involving them. ${ }^{34}$ Schools should be effective in engaging adolescents as they are establishing long-term habits related to NCD risk and seeking peer acceptance. Out-of-school adolescents may benefit from health messages disseminated through various social and electronic media. Future evaluations of indirect prevention efforts will contribute to the evidence base for prevention of NCDs through activities during adolescence.

How the education sector can contribute to the NCD prevention agenda will also depend on the extent to which in-school efforts can be augmented by policies targeting behavioural factors at or near school (eg, limiting the sale and marketing of unhealthy food and beverages, tobacco and alcohol nearby), and collection of data on child and adolescent health and NCD risk status, and their influence on children as change agents outside school. ${ }^{35}$ Improved cooperation between government health and education agencies for reliable periodic assessment of child NCD risk would be a major contribution.

Prevention of NCD risks will require private sector engagement in multiple sectors. Food and beverage production, marketing and media representation are particularly relevant to NCD risk reduction early in life. ${ }^{36}$ A regional study in Latin America and the Caribbean on the impact of food and beverage marketing on children provides related evidence. ${ }^{38}$ Financial incentives 


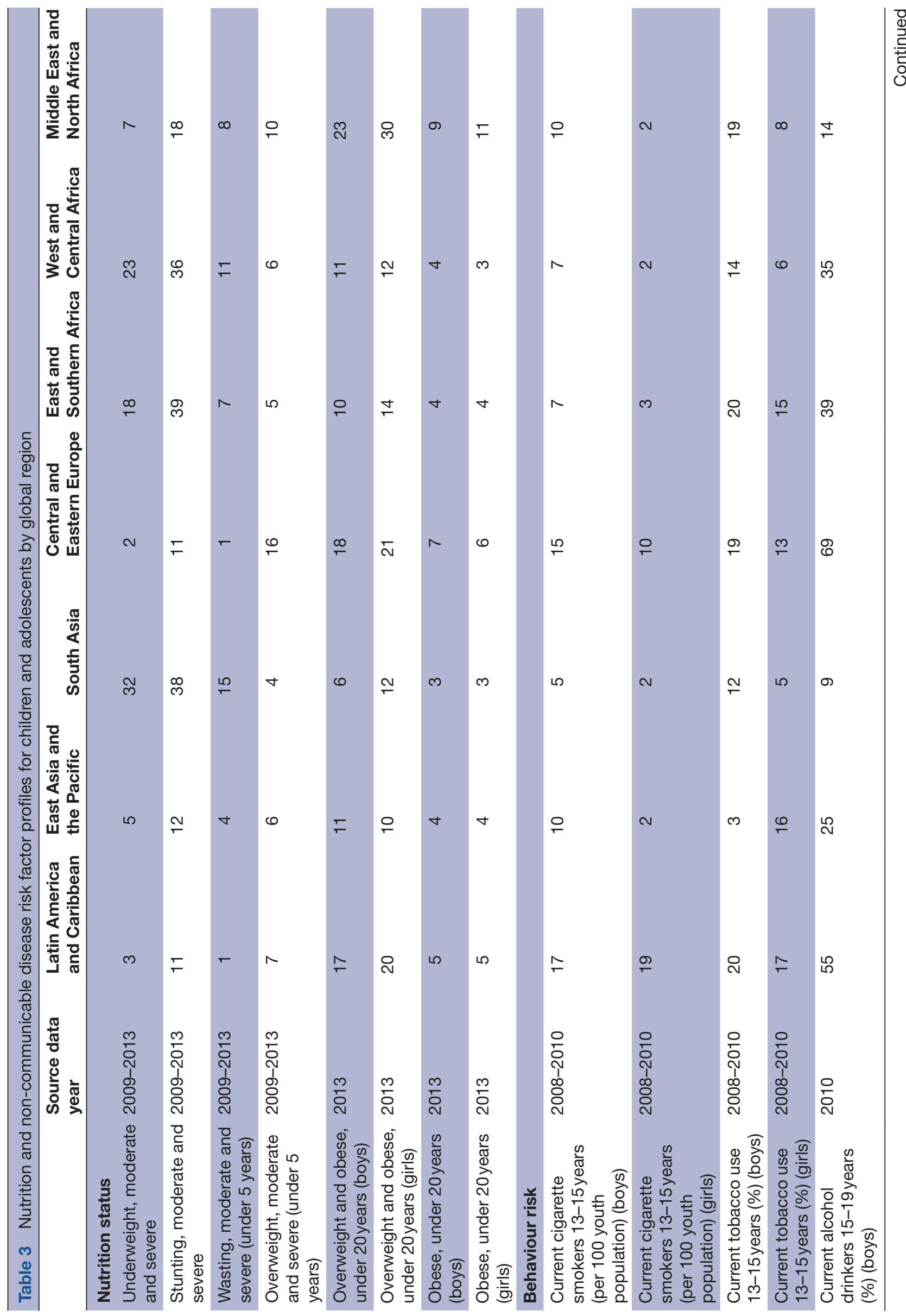

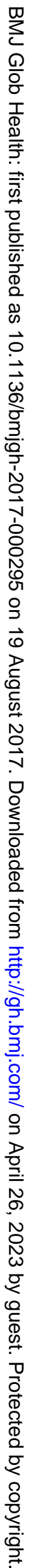


or disincentives for this industry related to unhealthy food consumption are needed. The tobacco industry provides an example: the gradual evolution of global restrictions on promotion of, taxes on and limiting the sale of tobacco products might equally be applied to calorie-rich or high sugar-containing or salt-containing processed food and drinks. Some countries have introduced related policies, for example, taxes on saturated fats or sugar-sweetened beverages to influence consumption. ${ }^{39-42}$ However, like tobacco control, these efforts faced significant opposition from key private stakeholders and required concerted effort and advocacy. ${ }^{43}$

State actions to reduce NCD risk might include related legislation, regulation of various sectors (food and beverage production and marketing, built environment design, some free public places), taxation or other disincentives, public funding for community initiatives and public amenity, and efforts to increase health literacy and related action. ${ }^{22}$ Regional public programmes can work with local authorities in their attempts to regulate increasingly well-resourced, coordinated, reluctant and often multinational private interests. As with tobacco, the efforts industries may make to avoid such regulation should not be underestimated. ${ }^{44}$ Some developed country initiatives in this area have already commenced.

Advocacy should be undertaken for including NCD risk reduction among children and adolescents in relevant government policies, and with costed plans. This includes policies that reduce children's and adolescents' direct and indirect exposure to tobacco, alcohol and drugs; limiting the promotion of unhealthy food and drinks, including through the media and at points of sale; integrating life skills and healthy living in school curricula; school-based annual screening for health status/NCD risk and provision/promotion of healthy food and physical activity; specific approaches to influence out-of-school youth and displaced populations; standards for the built environment and public amenity that foster physical activity and individual safety, especially in early life; assurance of funding for universal screening and simple treatment of NCDs across the life-cycle; and initiatives to improve related health literacy of the community at large. Actions appropriate to national or local contexts can be developed at country level, bearing in mind the evidence on what is effective.

To the extent that NCD prevention is a new area of focus for governments and development organisations alike, the financing and policy experience applied to other health programmes will be important. Examples may include the inclusion of NCD screening and prevention in existing subsidised or free primary care packages; costing and cost-benefit analyses for advocacy; and design, costing and piloting of welfare schemes (cash transfers, subsidies, vouchers and so on) that include NCD prevention, and health-focused or education sector-focused, performance-based NCD prevention, and community accountability schemes, among others. 
Analysis of the cost implications of inaction on NCD prevention during childhood and adolescence is needed to influence the policy dialogue at all levels.

\section{SUMMARY}

As the incidence of NCDs rises, the imperative to act on risk factors becomes more urgent. $\mathrm{MCH}$ programmes across the reproductive health life-cycle are strongly positioned to play an important role in NCD prevention given early life influences on NCD risks and outcomes. Such programmes should seek both to incorporate NCD prevention within existing services, while also broadening their scope to include older children and adolescents whose related behaviours set up lifetime patterns of risk. Many MCH activities readily contribute to NCD prevention, such as promotion of good health before conception and during pregnancy, breast feeding and appropriate early childhood nutrition, and emphasising physical activity during early childhood and at school. Refocusing these activities through an NCD prevention lens is an important public health opportunity. Expanding programmes to include older children and adolescents may reduce risk factors such as tobacco smoking and alcohol abuse.

Cross-sectoral involvement is necessary for making a meaningful impact on reducing NCD risk in early life. Many non-health sectors can impact NCD risk, and the SDG's emphasis on multisectorality supports the consideration of NCD risk reduction in many different sectoral programmes. A greater NCD prevention focus in schools should impact related behaviours and risk factors at individual and family levels. Policy, advocacy and legislation, particularly involving the food and beverage industry and the media, should also help children and adolescents to make healthy choices. Built environment initiatives can also improve opportunities for safe physical activity, beginning early in life.

Contributors LB: Conceptualised the paper, interpreted the findings of the literature reviews and wrote the paper. NRS: Conceptualised the paper interpreted the findings of the literature reviews and wrote the paper. AA: Undertook one of the literature reviews and interpreted the findings. SL: Contributed to writing the paper. DBH: Conceptualised the paper, interpreted the findings of the literature reviews, searched and interpreted additional literature, and wrote the paper.

Competing interests None declared.

Provenance and peer review Not commissioned; externally peer reviewed.

Data sharing statement Two unpublished literature reviews commissioned by Unicef New York and the Unicef Latin America and Caribbean Regional Office are cited in this paper, and are available for downloading and review in the public domain.

Open Access This is an Open Access article distributed in accordance with the Creative Commons Attribution Non Commercial (CC BY-NC 4.0) license, which permits others to distribute, remix, adapt, build upon this work non-commercially, and license their derivative works on different terms, provided the original work is properly cited and the use is non-commercial. See: http://creativecommons.org/ licenses/by-nc/4.0/

(c) Article author(s) (or their employer(s) unless otherwise stated in the text of the article) 2017. All rights reserved. No commercial use is permitted unless otherwise expressly granted.
REFERENCES

1. WHO. Global status report on noncommunicable disease 2014. Geneva: World Health Organization, 2014.

2. WHO. Global action plan for the prevention and control of noncommunicable diseases 2013-2020. Geneva: World Health Organization, 2013.

3. Forouzanfar MH, Alexander L, Anderson HR, et al. Global, regional, and national comparative risk assessment of 79 behavioural, environmental and occupational, and metabolic risks or clusters of risks in 188 countries, 1990-2013: a systematic analysis for the global burden of disease study 2013. The Lancet 2015;386:2287-323.

4. United Nations. Sustainable development goals-17 goals to transform our world. $2016 \mathrm{http} / / / w w w . u n . o r g / s u s t a i n a b l e d e v e l o$ pment/health/ (accessed $10 \mathrm{Apr}$ 2017).

5. WHO. 2016. Commission on Ending Childhood Obesity. Report of the Commission on Ending Childhood Obesity. Geneva: World Health Organization.

6. Hanson MA, Gluckman PD. Early developmental conditioning of later health and disease: physiology or pathophysiology? Physiol Rev 2014;94:1027-76.

7. Twig G, Yaniv $\mathrm{G}$, Levine $\mathrm{H}$, et al. Body-Mass index in 2.3 million adolescents and cardiovascular death in adulthood. N Engl $\mathrm{J}$ Med 2016;374:2430-40.

8. Mokdad AH, Forouzanfar MH, Daoud F, et al. Global burden of diseases, injuries, and risk factors for young people's health during 19902013: a systematic analysis for the Global Burden of Disease Study 2013. The Lancet 2016;387:2383-401.

9. Patton GC, Sawyer SM, Santelli JS, et al. Our future: a Lancet commission on adolescent health and wellbeing. The Lancet 2016;387:2423-78.

10. United Nations Secretary General. Global Strategy for Women's, Children's and Adolescents' Health. 2015 http://www. everywomaneverychild.org/global-strategy-2 (accessed $10 \mathrm{Apr}$ 2017).

11. Soubry A, Guo L, Huang Z, et al. Obesity-related DNA methylation at imprinted genes in human sperm: results from the TIEGER study. Clin Epigenetics 2016;8:51.

12. Hanson MA, Gluckman PD. Developmental origins of health and disease ? global public health implications. Best Pract Res Clin Obstet Gynaecol 2015;29:24-31.

13. Barouki R, Gluckman PD, Grandjean P, et al. Developmental origins of non-communicable disease: implications for research and public health. Environmental Health 2012;11:1-9.

14. Boney CM, Verma A, Tucker R, et al. Metabolic syndrome in childhood: association with birth weight, maternal obesity, and gestational diabetes mellitus. Pediatrics 2005;115:e290-6.

15. Black RE, Victora CG, Walker SP, et al. Maternal and child undernutrition and overweight in low-income and middle-income countries. The Lancet 2013;382:427-51.

16. Johnson MK, Crosnoe R, Elder GH. Insights on Adolescence from a Life Course Perspective. Journal of Research on Adolescence 2011;21:273-80.

17. Catalano RF, Fagan AA, Gavin LE, et al. Worldwide application of prevention science in adolescent health. The Lancet 2012;379:1653-64

18. Bay JL, Vickers MH. Adolescent education: an opportunity to create a developmental origins of health and Ddsease (DOHaD) circuit breaker. J Dev Orig Health Dis 2016;7:501-4.

19. Di Cesare M, Khang Y-H, Asaria P, et al. Inequalities in noncommunicable diseases and effective responses. The Lancet 2013;381:585-97.

20. Mmari K, Blum R, Sonenstein F, et al. Adolescents' perceptions of health from disadvantaged urban communities: findings from the WAVE study. Soc Sci Med 2014;104:124-32.

21. Sawyer SM, Afifi RA, Bearinger LH, et al. Adolescence: a foundation for future health. The Lancet 2012;379:1630-40.

22. Gortmaker SL, Swinburn BA, Levy D, et al. Changing the future of obesity: science, policy, and action. The Lancet 2011;378:838-47.

23. Gonzales M, Brumana L, Arroyo A. Systematic review of reviews of effective interventions in the life course of maternal-child and adolescence to prevent non-communicable diseases (NCDs) and its risk factors. Panama City: UNICEF Latin America and the Caribbean Regional Office, 2016. http://uni.cf/2cdbbUH.

24. UNICEF. Review of interventions to promote healthy behaviours for the prevention of non-communicable diseases among children and adolescents. $2016 \mathrm{https} / / / \mathrm{www}$.hashdoc.com/documents/389360/ ncd-evidence-revview (accessed 8 Apr 20117)

25. Frenk J, Gómez-Dantés O, Moon S. From sovereignty to solidarity: a renewed concept of global health for an era of complex interdependence. Lancet 2014;383:94-7. 
26. Victora CG, Bahl R, Barros AJ, et al. Breastfeeding in the 21st century: epidemiology, mechanisms, and lifelong effect. Lancet 2016;387:475-90.

27. Korpela K, Salonen A, Virta LJ, et al. Association of Early-Life Antibiotic Use and protective effects of Breastfeeding: role of the intestinal Microbiota. JAMA Pediatr 2016;170:750-7.

28. UN interagency Task Force on NCDs. Noncommunicable diseases and their risk factors. $2016 \mathrm{http} / / / w w w . w h o . i n t / n c d s / u n-t a s k-f o r c e /$ en (accessed 17 Apr 2017).

29. World Health Organization. Draft Updated Appendix 3 of the WHO Global NCD Action Plan 2013-2020. 2016 http://www.who.int/ncds/ governance/discussion-paper-updating-appendix3-25july2016-EN. pdf?ua=1 (accessed 10 Apr 2017).

30. Victora CG, Adair L, Fall C, et al. Maternal and child undernutrition: consequences for adult health and human capital. The Lancet 2008;371:340-57.

31. Swinburn BA, Sacks G, Hall KD, et al. The global obesity pandemic: shaped by global drivers and local environments. The Lancet 2011;378:804-14.

32. Langford R, Bonell CP, Hayley E, et al. The WHO Health Promoting School framework for improving the health and well-being of students and their academic achievement. Cochrane Database of Systematic Reviews 2014

33. Saydah S, Bullard KM, Imperatore G, et al. Cardiometabolic risk factors among US adolescents and young adults and risk of early mortality. Pediatrics 2013;131:e679-86.

34. Baker R, Taylor E, Essafi S, et al. Engaging young people in the prevention of noncommunicable diseases. Bull World Health Organ 2016;94:484.

35. UNICEF. Review of interventions to promote healthy behaviours for the prevention of non-communicable diseases among children and adolescents. New York: UNICEF, 2016.

36. Cairns G, Angus K, Hastings G, et al. Systematic reviews of the evidence on the nature, extent and effects of food marketing to children. A retrospective summary. Appetite 2013;62:209-15.

37. Lobstein T, Jackson-Leach R, Moodie ML, et al. Child and adolescent obesity: part of a bigger picture. The Lancet 2015;385:2510-20.

38. UNICEF. 2015. Exploratory study of marketing and advertisement of unhealthy food and beverages targeted to children in Latin America and the Caribbean (Executive Summary).

39. Falbe J, Rojas N, Grummon AH, et al. Higher Retail prices of SugarSweetened Beverages 3 months after implementation of an Excise tax in Berkeley, California. Am J Public Health 2015;105:2194-201.

40. Colchero MA, Popkin BM, Rivera JA, et al. Beverage purchases from stores in Mexico under the excise tax on sugar sweetened beverages: observational study. BMJ 2016;352:h6704.

41. Berardi N, Sevestre P, Tépaut M, et al. The impact of a 'soda tax' on prices: evidence from french micro data. Appl Econ 2016;48:3976-94.

42. Franck C, Grandi SM, Eisenberg MJ. Taxing junk food to Counter Obesity. Am J Public Health 2013;103:1949-53.

43. WHO. Using price policies to promote healthier diets. Copenhagen: World Health Organization, 2015.

44. Secombe M. Big tobacco's plan to stub out plain packaging. https:// www.thesaturdaypaper.com.au/opinion/topic/2014/03/08/bigtobaccos-plan-stub-out-plain-packaging/1394197200 (accessed 10 Apr 2017).

45. Haider BA, Bhutta ZA. Multiple-micronutrient supplementation for women during pregnancy. Cochrane Database Syst Rev 2015;11:CD004905.

46. Waters E, de Silva-Sanigorski A, Hall BJ, et al. Interventions for preventing obesity in children. Cochrane Database Syst Rev 2011;12:CD001871.

47. Knai C?cile, Pomerleau J, Lock K, et al. Getting children to eat more fruit and vegetables: a systematic review. Prev Med 2006;42:85-95.

48. Baird J, Cooper C, Margetts BM, et al. Changing health behaviour of young women from disadvantaged backgrounds: evidence from systematic reviews. Proceedings of the Nutrition Society 2009;68:195-204.
49. Rawal T, Singh A, Nazar G, et al. Impact of school policies on NCD risk factors-a systematic review. Asia-Pacific Journal of Clinical Oncology 2014:243-4.

50. Dudley DA, Cotton WG, Peralta LR. Teaching approaches and strategies that promote healthy eating in primary school children: a systematic review and meta-analysis. Int J Behav Nutr Phys Act $2015 ; 12: 28$

51. Liao Y, Liao J, Durand CP, et al. Which type of sedentary behaviour intervention is more effective at reducing body mass index in children? A meta-analytic review. Obesity Reviews 2014;15:159-68.

52. Seo D-C, Sa J. A Meta-Analysis of Obesity Interventions among U.S. Minority Children. J Adolesc Health 2010;46:309-23.

53. Foxcroft DR, Tsertsvadze A. Universal family-based prevention programs for alcohol misuse in young people. Cochrane Database Syst Rev 2011;9:CD009308.

54. Saraf DS, Nongkynrih B, Pandav CS, et al. A systematic review of School-Based interventions to prevent risk factors associated with noncommunicable diseases. Asia-Pac J Public Health 2012;24:733-52.

55. Pereira SG, Palmeira AL. Association between parental support and physical activity for children and teens. . Gymnasium: Revista de Educacao Fisica, Desporto e Saude, 2013:4. 101-29.

56. Biddle SJH, Petrolini I, Pearson N. Interventions designed to reduce sedentary behaviours in young people: a review of reviews. $\mathrm{Br} J$ Sports Med 2014;48:182-6.

57. Wang Y, Wu Y, Wilson RF, et al. Childhood Obesity Prevention Programs: comparative effectiveness review and Meta-Analysis. Rockville 2013.

58. Oude Luttikhuis $\mathrm{H}$, Baur L, Jansen $\mathrm{H}$, et al. Interventions for treating obesity in children. Cochrane Database Syst Rev 2009;1:CD001872.

59. Brand T, Pischke C, Steenbock B, et al. What Works in CommunityBased Interventions Promoting Physical activity and Healthy Eating? A review of reviews. Int J Environ Res Public Health 2014:11:5866-88.

60. Chen J-L, Wilkosz ME. Efficacy of technology-based interventions for obesity prevention in adolescents: a systematic review. Adolesc Health Med Ther 2014;5:159-70.

61. Hamel LM, Robbins LB. Computer- and web-based interventions to promote healthy eating among children and adolescents: a systematic review. J Adv Nurs 2013;69:16-30.

62. Carson KV, Brinn MP, Labiszewski NA, et al. Community interventions for preventing smoking in young people. Cochrane Database Syst Rev 2011;7:CD001291.

63. Brinn MP, Carson KV, Esterman AJ, et al. Mass media interventions for preventing smoking in young people. Cochrane Database Syst Rev 2010;11:CD001006.

64. Thomas RE, McLellan J, Perera R. School-based programmes for preventing smoking. Cochrane Database Syst Rev 2013;4:CD001293.

65. Thomas RE, Baker PR, Thomas BC, et al. Family-based programmes for preventing smoking by children and adolescents. Cochrane Database Syst Rev 2015;2:CD004493.

66. Emmers E, Bekkering GE, Hannes K. Prevention of alcohol and drug misuse in adolescents: an overview of systematic reviews. Nordic Studies on Alcohol and Drugs 2015;32:183.

67. WHO. Framework Convention on Tobacco Control. 2015 http://www. who.int/fctc/WHO_FCTC_summary_January2015_EN.pdf?ua=1 (accessed 10 Apr 2017).

68. World Health Organization. Global status report on alcohol and health. Geneva: WHO, 2014

69. Hillier-Brown FC, Bambra CL, Cairns J-M, et al. A systematic review of the effectiveness of individual, community and societal level interventions at reducing socioeconomic inequalities in obesity amongst children. BMC Public Health 2014; $14: 834$

70. Vos T, Barber RM, Bell B, et al. Global, regional, and national incidence, prevalence, and years lived with disability for 301 acute and chronic diseases and injuries in 188 countries, 1990-2013: a systematic analysis for the global burden of disease study 2013. The Lancet 2015;386:743-800. 